\title{
Effect of B Content on the Microstructure and Properties of As-cast TC4/B
}

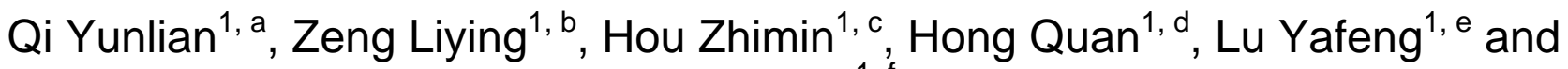 \\ Zhao Bin ${ }^{1, f}$ \\ ${ }^{1}$ Northwest Institute for Nonferrous Metal Research, Xi'an 710016, PR China \\ aqiyunlian@126.com, bZENG-ly@163.com, chouzhimin_2003@yahoo.com.cn, \\ dhongquan@c-nin.com, ${ }^{\mathrm{e}}$ TARC@c-nin.com, 'zhaobin_51@126.com
}

Keywords: Cast titanium alloy; TiB; Elastic modulus; Microstructure and Mechanical properties

\begin{abstract}
In this paper, the TC4 titanium matrix composite were fabricated by melting-casting process, the composite was reinforced with different content of B ranging from $0.2 \mathrm{wt} \%$ to $1.0 \mathrm{wt} \%$. The microstructure and mechanical properties of as-cast TC4/B titanium matrix composite were investigated. The results indicate that the elastic modulus increase $15 \%-30 \%$ for TC4/B composite with $0.2 \mathrm{wt} \%$ to $1.0 \mathrm{wt} \% \mathrm{~B}$. The microstructures of as-cast $\mathrm{TC} 4 / \mathrm{B}$ are consisted of lamellar $\alpha$, grain boundaries $\beta$ and the second phase of $\mathrm{TiB}$, and the second phase TiB aggregates at the prior- $\beta$ grain boundaries with necklace-like arrangement. The microstructures of TC4/B would refine with the increath of B content. From the analysis of fractographies, it can be found that with the increasing of $\mathrm{B}$ content, the fracture model transforms from typical intergranular fracture to mixed fracture.
\end{abstract}

\section{Introduction}

Titanium and titanium alloy castings have found more and more applications in aerospace and advanced weapons industries. And especially in recent years, with the technology improvement of the investment casting for titanium, some complex equipment parts made by batch casting are possible. So, the material utilization can be improved, the production cycle will be shortened, and the manufacturing cost of equipment parts can be reduced sharply by the near-net shaping technology. At present, more than $80 \%$ titanium alloy castings are made of Ti-6A1-4V alloy (referred to as TC4 hereafter) for aerospace industry in China [1-2].

Compared to other high strength engineering materials, the elastic modulus of titanium alloy usually varies from $110 \mathrm{GPa}$ to $125 \mathrm{GPa}$, which is about $1 / 2$ of the steel. Because of its low rigidity, long and thin wall titanium components are easy to be distorted during the service life, so how to improve the comprehensive performances of titanium alloys has always been concerned by many researchers. Generally speaking, the elastic modulus of alloys is mainly related to alloy composition and phase composition. The elastic modulus can be improved obviously for the alloys with compounds such as $\mathrm{TiB}, \mathrm{TiC}$ and $\mathrm{Ti}_{3} \mathrm{Al}$, and also with higher amount of $\alpha$ stable elements and $\alpha$ phase volume fraction. The elastic modulus of TiB phase is as high as $350-550 \mathrm{GPa}$, so it can significantly improve the elastic modulus of titanium alloys. On the other hand, the grain size will be refined, the strength and stiffness can be increased with the adding of element boron (referred to as B hereafter) in traditional titanium alloy castings. Then, in order to improve the performance of the traditional titanium alloys, new, economic and practical processes can be developed according to above mentioned methods [3-5]. The microstructure and the mechanical properties of the as-cast TC4 bars with $0.2 \mathrm{wt} . \%-1.0 \mathrm{wt} . \%$ element $\mathrm{B}$ are to be investigated in this paper.

\section{Materials and Experiment}

Raw materials used in this experiment were titanium sponge, aluminum shots, pure vanadium, pure B powder, titanium foil, they were mixed in a certain proportion and were pressed into electrode block. Three kinds of TC4-xB titanium matrix composite, where $\mathrm{x}=0.2 \mathrm{wt} . \%, 0.5 \mathrm{wt} . \%$ and $1.0 \mathrm{wt} . \%$, 
were prepared by induction melting furnace pre-melting for one time and by non-consumable vacuum arc furnace melting for 4 times. Then the as-cast composite bars with the length of $100 \mathrm{~mm}$ and diameter of $8 \mathrm{~mm}$ were casted in a red copper mould. The bars were hot isostatic pressed (HIPed) at $920{ }^{\circ} \mathrm{C}$ with the pressure of $110 \mathrm{MPa}$ for $2 \mathrm{~h}$ to reduce the cast porosity. The samples for phase composition and microstructure analysis were in length of $10 \mathrm{~mm}$ and diameter of $8 \mathrm{~mm}$. The samples for mechanical property tests were in length of $40 \mathrm{~mm}$ and diameter of $8 \mathrm{~mm}$.

\section{Results and Discussion}

The influence of B on elastic modulus of TC4 / B.

Fig.1. shows a curve of elastic modulus of TC4 / B titanium matrix composite vs. boron content. From the figure, it can be seen that the elastic modulus for the as-cast matrix TC4 alloy is less than $110 \mathrm{GPa}$, and which is more than $125 \mathrm{GPa}$ for the composite with $0.2 \mathrm{wt} \% \mathrm{~B}$, the value increases $34 \%$ due to the formation of TiB reinforcing phase. With the adding of element boron, the elastic modulus for the composite increases first and then decrease. When B content is $0.5 \mathrm{wt} \%$, the elastic modulus of the composite reaches a maximum value of $145 \mathrm{GPa}$.

\section{The influence of B on the mechanical properties of TC4 / B at room temperature.}

The mechanical properties at room temperature of the as-HIPed TC4/B titanium matrix composite bars are shown in Fig. 2 . When boron content increases from $0.2 \mathrm{wt} \%$ to $1.0 \mathrm{wt} \%$, the tensile strength of the composite increases from $995 \mathrm{MPa}$ to $1205 \mathrm{MPa}$, the increment is about $21 \%$. At the same time, the yield strength has the same changing tendency compared with the tensile strength, and its increment is $20 \%$ or so. On the contrary, the elongation and the reduction of area have reverse tendency, they both decrease with the increment of element B. When boron content varies from $0.2 \mathrm{wt} \%$ to $1.0 \mathrm{wt} \%$, the elongation reduces from $10.8 \%$ to $3.8 \%$, the descending rate is about $65 \%$. And the reduction of area reduces from $27.0 \%$ to $10.8 \%$, the descending rate is $60 \%$.

To sum up, with the adding of the element boron, the reinforcing phase TiB can improve the strength of TC4/B, and greatly reduce the plastic of the composite at the same time. The effect will be more obvious with higher amount of element B. The reason for the decrease of plasticity is mainly due to the higher volume fraction of the TiB particles with the increase of boron content. Hard and brittle TiB phases gather in grain boundaries, which can offset the effect of grain refinement, and limit the alloy plasticity [5].

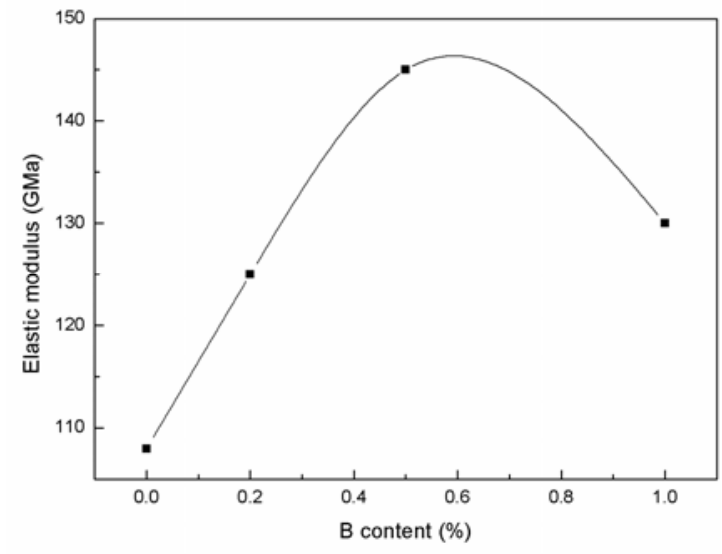

Fig. 1. Elastic modulus of TC4/B titanium matrix composite

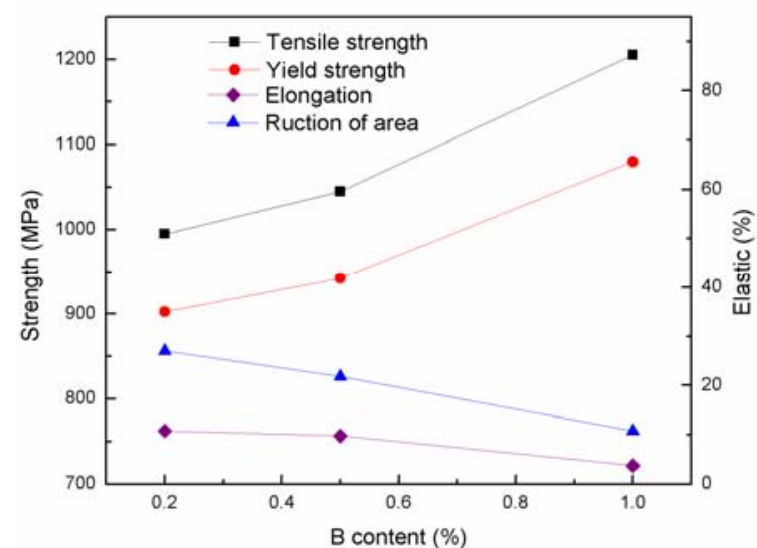

Fig.2. Mechanical properties of TC4/B titanium matrix composite at room temperature

The influence of $B$ on the microstructure and the tensile fracture of TC4 / B .

The microstructures of TC4/B composite with different boron content are shown in Fig.3. The microstructures of the composite are consisted of lamellar $\alpha$, grain boundary $\beta$ and the second phase of $\mathrm{TiB}$, and $\mathrm{TiB}$ phases aggregate at the prior- $\beta$ grain boundaries with necklace-like arrangement. With the increath of B content, the volume fraction of second phase TiB increases significantly, and more and more fine grains can be found. When B content is $0.2 \mathrm{wt} \%, 0.5 \mathrm{wt} \%, 1.0 \mathrm{wt} \%$, the shape of internal $\alpha$ grains are long and thick strips, short and thick strips, at last refine to needle or long and 
thin strips, as shown in Fig.3a, Fig.3b and Fig.3c, respectively. The adding of element B can not only refine the grains of the composite, but also can refine the grains of internal $\alpha$ layers [5].

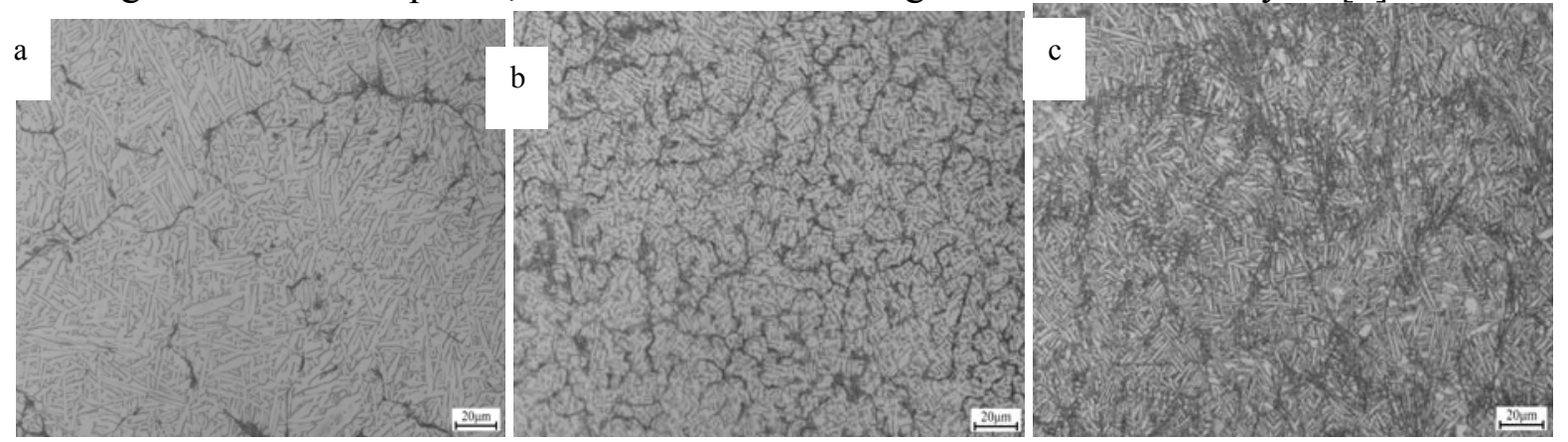

Fig.3. The microstructure of TC4/B composite with different $\mathrm{B}$ content
(a) $0.2 \mathrm{wt} \% \mathrm{~B}$
(b) $0.5 \mathrm{wt} \% \mathrm{~B}$
(c) $1.0 \mathrm{wt} \% \mathrm{~B}$

SEM images of fractographies of TC4/B titanium matrix composites with different B content are shown in Fig.4. From Fig.4a, c, it can be seen that the fracture surface is smooth without obvious necking phenomenon, and secondary cracks can also be found in these two figures. The fracture surface in Fig.4e is more plain than that in Fig.4a, c. There are some small holes and without secondary cracks on the fracture surface. Clear tear ridge can be seen on the fracture surface shown in Fig.4b, d. Most of the uniform dimples are broad and deep, as shown in Fig.4b. The dimples in Fig.4d are shallower than that in Fig. $4 \mathrm{~b}$, the fracture surface with intergranular fracture and the secondary cracks is the typical feature of intergranular fracture. Small cleavage plane and a large number of long strips fracture plane can be found in Fig.4f. The analysis shows that the long strips fracture plane is corresponding to the lamellar $\alpha$ phase. So the fracture propagates along lamellar $\alpha$ phase [6-8].
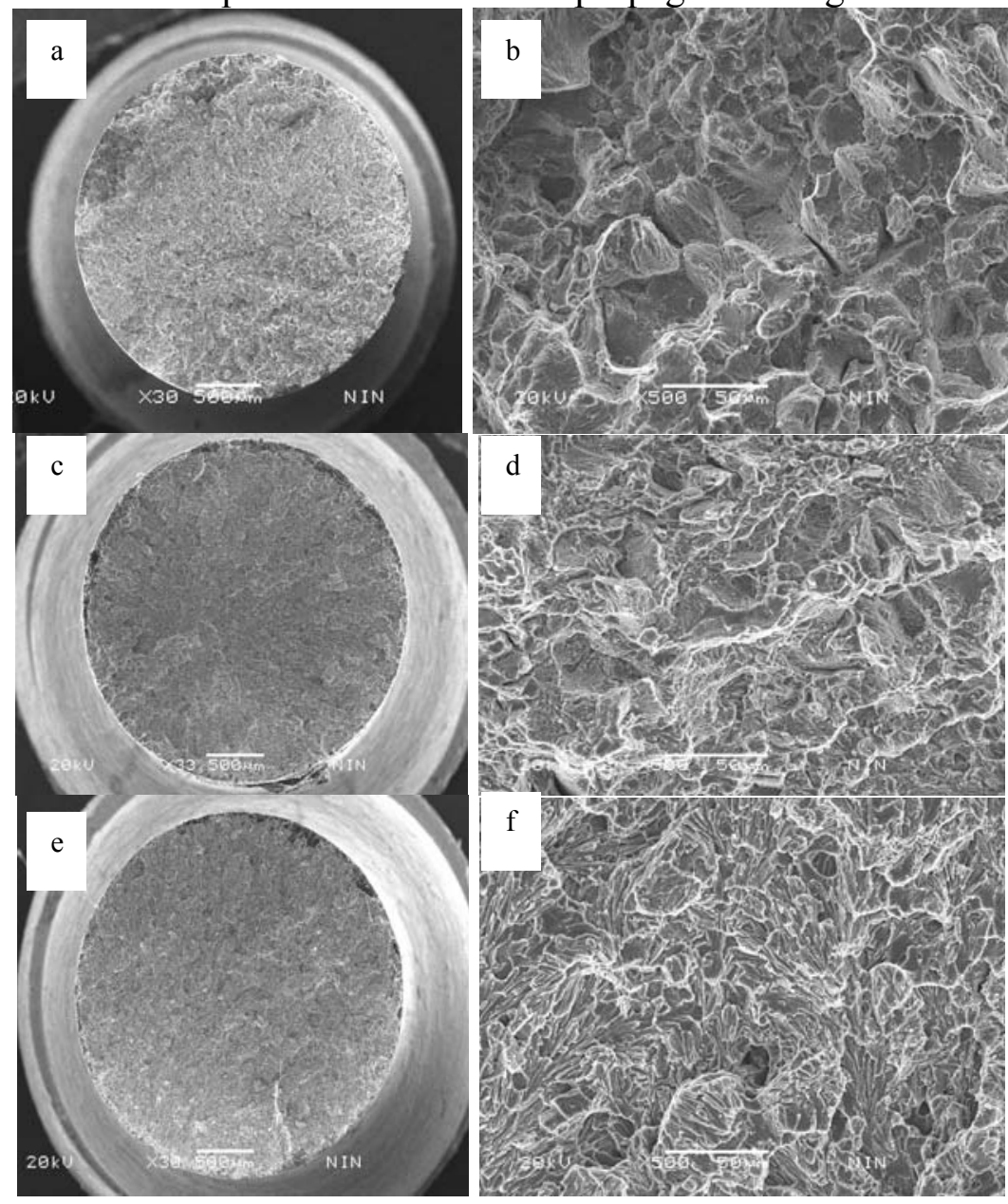

Fig.4. SEM images of fractographies for TC4/B titanium matrix composite (a, b) $0.2 \% \mathrm{~B},(\mathrm{c}, \mathrm{d}) 0.5 \% \mathrm{~B},(\mathrm{e}, \mathrm{f}) 1.0 \% \mathrm{~B}$. 


\section{Conclusions}

1) The second phase of TiB can improve the elastic modulus of as-cast TC4/B titanium matrix composite. The elastic modulus can be improved $15-30 \%$ for the composite with $0.2 \mathrm{wt} \%$ to $1.0 \mathrm{wt} \%$ element $\mathrm{B}$. The reinforcing phase of $\mathrm{TiB}$ can increase strength, and greatly reduce the plasticity of the composite. The effect will be more obvious with higher amount of element B.

2) The microstructures of as-cast TC4/B composite are consisted of lamellar $\alpha$, grain boundary $\beta$ and the second phase of $\mathrm{TiB}$, and $\mathrm{TiB}$ phases aggregate at the prior- $\beta$ grain boundaries with necklace-like arrangement. The microstructures of the composite would refine with the increasing of B content.

3) From the analysis of fractographies, it can be found that with the increasing of B content, the fracture model transforms from typical intergranular fracture to mixed fracture.

\section{References}

[1] P.Yan, L.Wang, J.Zhao, Z.H.Wang, C.H.Zhang and T.You: Foundry,Vol. 56 (2007) No.5, p. 451-454.

[2] G.Q.Su, H.S.Xie, C.H.Zhang, J.Zhao, L.Wang, Z.Q.Yu and H.Y.Liu: Titanium Industry Progress, Vol. 22 (2005) No.2, p. 26.

[3] Z.H.Zhang, X.Z.Wang, S.L.Shang, K.W.Bai and J.Y.Shen:Rare Metal, Vol. 25 (2001) No.1, p. $19-22$.

[4] S.Z.Zhang, J.F.Lei, S.X.Guan, Y.Y.Liu and D.Li:Acta Metallrugica Sinice, Vol. 38 (2002), p. 74-77.

[5] H.Luo and Z.Q.Chen: Development and Application of Materials, Vol. 25 (2010) No.4, p.77-80.

[6] Y.X.Cui and C.L.Wang: Analysis of metal fracture surface (Harbin Institute of Technology Publications, Chnia1998), p. 34-216.

[7] M.H.Zhao, J.Zhang and D.Feng: Fracture analysis of high temperature alloy (Metallurgical Industry Press, Chnia2006), p.119-177.

[8] W.J.Jia, W.D.Zeng, H.Q.Yu and Y.G.Zhou: The Chinese Journal of nonferrous metals, Vol. 19 (2009) No.6, p. 1032-1027. 